\title{
Study on the Application of Learning Portfolio Evaluation in the Development of English Subject Literacy of Vocational College Students
}

\author{
Weiwei Liu \\ Basic Teaching Department \\ Shandong Huayu University of Technology \\ Dezhou, Shandong, China \\ 673559273@qq.com
}

\begin{abstract}
With the deepening of the reform of English courses in higher vocational colleges, accelerating the in-depth integration of information-based teaching and subject teaching, and improving the evaluation system of English courses are two effective ways to promote the effective development of students' core literacy. More and more teachers and educators pay attention to the quality of personnel training. Learning portfolio evaluation is one of the important means of the formative evaluation of English subjects. It can not only fully mobilize the students' initiative, promote the setting of students' goals, selfreflection and evaluation, but also collect students' information and materials from various angles. It plays an important role in promoting the goals of teaching and learning. This paper discusses the design ideas, design schemes and incentive effects of the reading and writing combination of vocational college students in the "Rain classroom + Flipped classroom" teaching mode (referred to as "Double Classroom") of higher vocational English. It discusses the scientific application of learning archives in the English cultural literacy of vocational college students. It also provides a reference for the evaluation and development of non-English majors' core literacy in higher vocational colleges.
\end{abstract}

Keywords-"Double Classroom" teaching; learning portfolio; English subject literacy; formative evaluation

\section{INTRODUCTION}

The "Education Informatization 2.0 Action Plan" points out that it is necessary to accelerate the in-depth integration of informatization teaching and subject teaching, and promote the high-order evolution of education informatization from converged application to innovation development. Information technology and intelligent technology are deeply integrated into the whole process of education.[1] It emphasizes the need to teach students in accordance with their aptitude, and to cultivate students' Chinese feelings, international vision and cross-cultural communication skills, critical thinking skills, and independent learning ability. The core literacy in the English subject is the correct outlook on life, values, morality, essential character and key ability gradually formed by students through English learning. It includes language ability, cultural awareness, thinking quality and learning ability. A concentrated expression of human values. How to evaluate students' English subject quality? How to use scientific, reasonable and effective evaluation methods to promote the

This work was supported by the projects of vocational education teaching reform research project in Shandong Province in 2017 (Project Code: 2017306) formation and development of students' core literacy of English subjects has become a close concern of the majority of educators and frontline teachers.

In order to further accelerate the integration of information teaching and college English subjects, we have built a "rain classroom + flipped classroom" teaching mode (referred to as "Double Classroom") in vocational English teaching. It not only reflects the students' individual development, promotes the scientific evaluation system of students' comprehensive and healthy development, but also has carried out two years of College English teaching practice. Using mobile phones and WeChat as carriers, the rain classroom---this new lightweight and convenient teaching tool is used as a means to implement flipping classroom teaching in vocational English teaching, so that teachers can know the details of the entire learning session.[4] The data can be used to understand the relationship between teachers and students, and improve the effectiveness of teaching and the quality of talent training for higher vocational students. At the same time, in order to better carry out the formation evaluation, highlight the cultivation of the core literacy of the higher vocational students, and design a more diverse and reasonable test activities, we have adopted the ways and methods of learning portfolios for students. This paper first introduces the definition, function and implementation steps of the learning portfolio. Secondly, taking the reading and writing portfolio of the vocational students as an example, the design method of the learning portfolio is discussed. Finally, the improvement suggestions are proposed for the shortcomings of the design. It is expected to provide a valuable reference for the first-line vocational English teachers to use the learning portfolio to promote and develop the core literacy of students' English subjects.

\section{LEARNING PORTFOLIOS: DEFINITIONS, ROLES, AND IMPLEMENTATION STEPS}

\section{A. Learning Portfolio Definition}

The learning portfolio is a collection of materials based on the learning and growth process of the students. The materials collected by the teachers or students over a long period of time and systematically reflect the efforts, progress and achievements of the students. It mainly 
including students, students' works, students' self-reflection and self-evaluation of the works.[2]

\section{B. The Role of the Learning Portfolio}

The learning portfolio has a guiding and stimulating role. The results of a student's output completed in a long learning phase form a learning portfolio. It allows students to experience the efforts, progress and achievements of their own learning over a period of time. On the other hand, the basis for the formative evaluation can provide teachers and students with a record of the learning process and progress at the end of the semester. Meanwhile, it is also an important form of demonstrating the dynamic learning process of students.

\section{Implementation of the Learning Portfolio}

The implementation steps of the learning portfolio can be divided into the setting of evaluation objectives and content, the information collection of students in the reflective learning process, teacher records and teacher feedback. Among them, the scientific and reasonable design scheme is the prerequisite for the implementation of the learning portfolio. The selfreflection link is an important part of the implementation of the learning portfolio. There are many issues to be considered in the design, such as what the purpose of establishing the portfolio is, and what the content includes. The self-reflection link can not only scientifically guide students to conduct effective self-learning evaluation, better understand their own deficiencies, but also provide teachers with an in-depth understanding of students and build a bridge of deep communication between teachers and students.

\section{The DESIGn AND ANALysis of READING AND WRiting PoRTfoliO}

\section{A. Design ideas[3]}

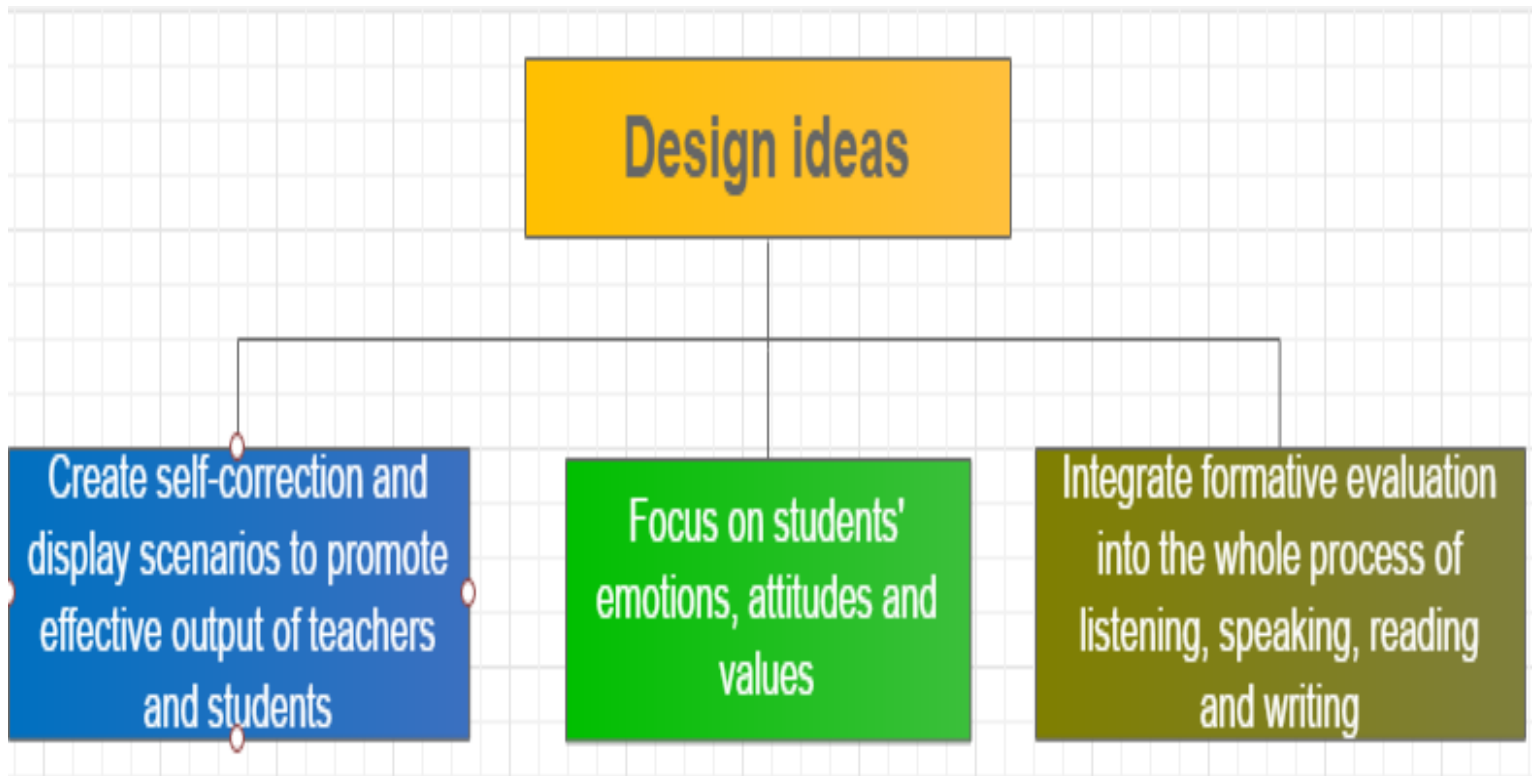

Fig. 1 The Structure of Design ideas 


\section{B. Design plan and promotion function}

\section{The design and analysis of reading and writing portfolio}

\section{Evaluation target:}

\section{Reading and writing portfolio}

1. Reading the portfolio: By reading the design of the portfolio, students can: develop students' critical thinking ability; read articles to form a reading of no less than 5,000 words Notes and 1000 words of reading experience; through the implementation of flipped classroom activities to share the reading process, improve students' speaking skills and writing skills; develop students' creativity, so that students can fully reflect and exert students' imagination by setting and completing group tasks of flipped classroom activities force.

2. Writing portfolio: Through the design of the writing portfolio, students can: accumulate and apply certain vocabulary and grammar knowledge; gain knowledge and skills in English writing (especially applied writing); cultivate good writing interest and develop Good writing habits; improve students' critical thinking ability and self-reflection ability.

Evaluation target: 18 higher vocational students

Evaluation period: 16 weeks

Reading content: Encourage students to read widely, expand the knowledge of students by reading materials of different themes and genres, enrich the reading experience, and open up students' horizons. Specific requirements are as follows:

1. Read at least one English word. You can choose a novel, a story or a literary classic. Complete 5000 English reading notes and 1000 reading experience (book review), the cover format is unified, the inner core design is designed by the students themselves, giving full play to the students' creativity.

2. Read at least 3 argumentative papers. You can choose the theme you like or care about.

Writing content: Encourage students to develop a good habit of one week, and gradually improve students' writing skills. Specific requirements are as follows:

1. List high-frequency words, phrases, and patterns in writing and try to use them in writing.

2. Reflect on the shortcomings of the first essay of this semester.

3. Analyze the best composition of the semester to find out the good sentences and writing skills used.

4. Choose the writing task you think is the hardest this semester and share the process and experience of overcoming this difficulty.

5. Self-evaluate the final essay of this semester, compare it with the first essay, reflect on his own progress and deficiencies, and complete a summary of writing progress. (including the skills of writing, the lack of progress, and the areas that need improvement in the future)

Sharing Experience in a Flipped Classroom:

1. Set up a class reading interest group and writing team. Each team consists of no more than 6 people and a team leader is established.

2. Regularly hold reading and writing experience sharing activities (the last class in a single month is a reading sharing event; the last class in a double week is a writing sharing event). For each member's sharing performance, feedback is given from three dimensions: individual, group and teacher, and the contents of the portfolio are adjusted in time.

Evaluation criteria for portfolios:

1. Content integrity (20\%)

The reading and writing content should be comprehensive, provide a detailed catalogue, and bind in the order of materials to ensure that there is no omission.

2. Quality of self-reflection and summarization (50\%)

In the portfolio of reading and writing, students need to have their own self-reflection and summary materials. It is recalled that the growth process in reading and writing.

3. Level of participation and completion of flipping classroom activities (20\%)

4. The aesthetics of the reading and writing materials (10\%)

\section{Features of reading and writing portfolios}

1) Highlights the development of students' core literacy and their dominant position in the evaluation. The evaluation objectives cover language application ability, cultural awareness, thinking quality and students' self-learning ability.

2) Flipped classroom teaching activities highlights the "student-centered" teaching concept, and promotes the exchange of information between teachers, students and students through interactive activities, such as "reading and sharing" and "writing salon".

3)Achieved the teaching purpose of "promoting teaching by evaluation" and "promoting learning by evaluation". The structure of the multi-dimensional perspective of assessing the core literacy of students' English subjects in the formative evaluation is perfected, which fully reflects the purpose of evaluation as a teaching service. 


\section{Learning Portfolio Improvement Suggestions}

After a one-semester study of the archives teaching practice of the experimental class, it has achieved certain results in the improvement of English subject quality, but it still needs continuous improvement to further meet the development needs of students' academic literacy. In view of the shortcomings of reading and writing portfolios, suggestions for improvement are proposed to enable students to promote the core literacy development of students more effectively and to further optimize the learning portfolio. The details as follows:

1. The timing of the staged evaluation in the evaluation cycle is scientifically to be improved. In a cycle of portfolio evaluation, teachers should set the cycle of each task scientifically and reasonably, so that they can have enough time to collect relevant information and self-reflection, and improve students' staged learning outcomes.

2. The content arrangement should fully reflect the laddertype. Teachers should set different levels of difficulty and gradient tasks according to the characteristics and basic level of the students in the class. Students with better foundations can emphasize the reading of original English works to enhance students' contrasting feelings between Chinese and Western literary works and improve students' Cross-cultural cognitive ability.

\section{CONCLUSION}

In summary, based on the in-depth analysis of the talent training objectives of higher vocational students, the use of scientific student learning portfolio has a strong rebuttal to promote the quality of English teaching in higher vocational schools. For students, the learning portfolio provides a good platform for students to self-recognize and self-display. At the same time, it also makes students understand that the visualization goal of the progress process has become a reality. For teachers, learning portfolios is a comprehensive understanding of students and promotion. The development of students' individuality and the concept of teaching students in accordance with their aptitudes provide the possibility. At the same time, it also perfects the structure of the multidisciplinary evaluation system for vocational English under the "Double Classroom" teaching mode, which lays a good foundation for further improving the quality of talent training for higher vocational students.

\section{ACKNOWLEDGMENTS}

This work was supported by the projects of vocational education teaching reform research project in Shandong Province in 2017 (Project Code: 2017306)

\section{REFERENCES}

[1] Education Informationization 2.0 Action Plan. Ministry of Education. 2018.4

[2] Luo Shaoqi, Liu Liping. English classroom evaluation to promote learning[M], English learning (teacher version). 2017 (9): 33-39

[3] Gearhart M\& Herman J L. Portfolio assessment: Whose work is it? Issues in the use of classroom assignments for accountability[J]. Educational Assessment, 1998, 5(1):41-55

[4] Liu Weiwei. An Applied Empirical Research on the Teaching Mode of 'Double Classroom' in College English Teaching of Higher Vocational Colleges.2019 International Conference on Education [J]. Management, Social Science and Humanities Research April 13-14 2019, PP.949-954

[5] He Kekang. From the essence of "flipped classroom", look at the future development of "flipped classroom" in China [J]. Research in AudioVisual Education, 2014, (07).

[6] Jiang Wei, Fei Hongxiao, Ling Ruixuan. Research on university wisdom classroom based on mobile internet [J]. China Education Informatization, 2016, (01).

[7] He Kekang. From the essence of "flipped classroom", look at the future development of "flipped classroom" in China [J]. Research in AudioVisual Education, 2014, (07).

[8] Enfield J. Looking at the Impact of the Flipped Classroom Model of Instruction on Undergraduate Multimedia Students at CSUN. TechTrends, 2013, 57(6), pp. 14-27.

[9] Paulson F L, Paulson P R\& Meyer C A. What makes a portfolio a portfolio? [J]. Educational Leadership, 1991, 48(5): 60-63

[10] Smith K \& Tillema H. Clarifying different types of portfolio use [J] Assessment \& Evaluation in Higher Education, 2003, 28(6):625-648.

[11] Gong Yafu, Luo Shaoqi. English Teaching Assessment [M]. Beijing: People's Education Press. 2002

[12] Li Zhaozeng. The Application of Portfolio Evaluation in English Learning. Contemporary education science. 2003.2

[13] Airasian. Classroom Assessment. New York: McGraw-Hill, Inc. 1997

[14] Hamp-Lyons, L., \&W. Condon. Assessing the Portfolio: Principles for Practice, Theory, and Research [M].NJ: Hampton Press, Inc., 2000.

[15] An Shuhong, On the cultivation of students' self-evaluation awareness combined with portfolio evaluation, 2009.12 